11. F. G. Will, C. D. Iacovangelo, J. S. Jackowski, and F. W. Secor, U.S. Department of Energy, Final Report C00-2950-1 (1978).

12. A. H. Compton and S. K. Allison, "X-Rays in Theory and Experiment," p. 38, D. Van Nostrand
Co., Inc., New York (1940).

13. H. A. Liebhafsky, H. G. Pfeiffer, E. H. Winslow, and P. Zemany, "X-Rays, Electrons, and Analytical Chemistry," pp. 525-528, Wiley-Interscience, New York (1972).

\title{
Shifts in Redox Formal Potentials Accompanying the Incorporation of Cationic Complexes in Perfluoro Polycarboxylate and Polysulfonate Coatings on Graphite Electrodes
}

\author{
Yu-Min Tsou and Fred C. Anson* \\ California Institute of Technology, Arthur Amos Noyes Laboratories, Division of Chemistry and Chemical Engineering, \\ Pasadena, California 91125
}

\section{ABSTRACT}

The formal potentials of several redox couples incorporated in coatings of a perfluoropolycarboxylate on graphite electrodes were measured and compared with the formal potentials of the same couples in homogeneous solution. The differences observed agreed with those calculated from the Nernst equation with the independently measured incorporation coefficients for both halves of the redox couples. The dependences of the shifts in formal potentials on the nature of the incorporating complex ion, the ionic strength, and the temperature were determined and indicated that the incorporation equilibrium is governed by electrostatic and hydrophobic interactions that act in opposite directions. The incorporation of most cations examined was driven by large increases in entropy which overcame the usually unfavorable enthalpy changes.

Redox reactants incorporated in polyelectrolyte coatings on electrode surfaces will exhibit formal potentials that are shifted from their values in solution whenever the two oxidation states of the reactant have different equilibrium constants for incorporation by the polyelectrolyte. This situation has been recognized in earlier reports $(1,2)$ and in a recent study this aspect of the electrochemistry of redox polymer coatings was examined in detail (3). In continuing studies of the electrochemical responses obtained from redox reactants at electrodes coated with Nafion, I, and the related polyelectrolyte, II,

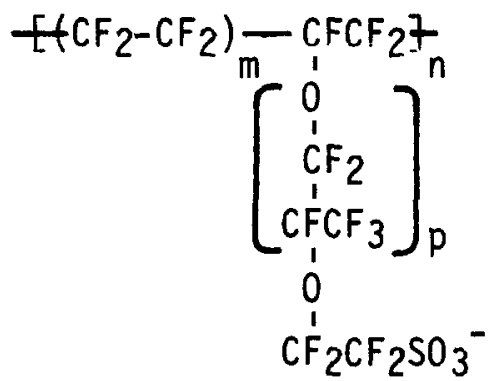

Nafion<smiles>CC(C)(C)[14CH3]</smiles>

Polyelectrolyte II

we noted unusually large shifts in the formal potentials of certain redox couples upon incorporation into these coatings. Both the magnitude of the shift in formal potential and its sign were influenced strongly by the nature of the ligands coordinated to the metal center of the redox couples. It was the purpose of the experiments described here to document the behavioral differences observed with several redox couples in both polyelectrolytes and to attempt to understand their origins. The results indicate that both electrostatic and hydrophobic interactions of incorporated electroactive ions with the polyelectrolyte combine to determine the direction of shifts in formal potentials. The temperature dependences of the shifts in formal potential were also measured. They pointed to large entropic contributions to the differences in the equilibrium incorporation of the oxidized and reduced halves of the redox couples.

\section{Experimental}

Materials.-Nafion ${ }^{1}$ coatings were prepared as previously described (4) by evaporation of aliquots of a solution of the polymer supplied by E. I. du Pont de Nemours and Company several years ago. Polymer II was supplied in the form of a fine suspension of the methyl ester by Asahi Glass Company, Tokyo. To prepare coatings, aliquots of the suspension were evaporated on freshly cleaved electrodes. The resulting deposit was exposed to $1 M \mathrm{NaOH}$ for $5 \mathrm{~min}$ to convert the ester to the carboxylate, and the electrode was then washed thoroughly with water. The extent and uniformity of the de-esterification were not examined in detail, but it was established that increasing the time that the coatings were exposed to the $1 M \mathrm{NaOH}$ produced no changes in their behavior. Electrodes were prepared from pyrolytic graphite (Union Carbide Company, Chicago) and mounted according to previously described procedures (5). $\mathrm{Ru}\left(\mathrm{NH}_{3}\right)_{6} \mathrm{Cl}_{3}$ (MatheyBishop Company) was recrystallized before use.

$\left[\mathrm{CpFeCp}-\mathrm{CH}_{2}-\mathrm{N}+\left(\mathrm{CH}_{3}\right)_{3}\right] \mathrm{Br}^{-}(\mathrm{Cp}=$ cyclopentadienide) (Research Organic/Inorganic Company) was used as received. $\mathrm{Ru}\left(\mathrm{NH}_{3}\right)_{5}$ isonicotinamide $\left(\mathrm{ClO}_{4}\right)_{2}(6)$ and $\left.\mathrm{Os}(\mathrm{bpy})_{3} \mathrm{ClO}_{4}\right)_{2}$ (7) were synthesized according to the cited references. Solutions were prepared with distilled water. which was further treated by passage through a purification train (Barnstead Nanopure).

${ }^{1}$ Nafion is a trademark of E. I. du Pont de Nemours and Company. 
Procedures.-Conventional two-compartment cells and apparatus were employed to obtain cyclic voltammograms. To evaluate formal potentials for reactants incorporated in electrode coatings, the cyclic voltammograms were recorded at scan rates low enough (e.g., a few $\mathrm{mV} \mathrm{s}^{-1}$ ) to obtain symmetrical waves with almost equal peak potentials. The quantities of the oxidized and reduced halves of redox couples incorporated by coatings were measured chronopotentiometrically (8) to avoid possible alterations in the equilibrium ratio of oxidant to reductant by insufficiently precise potentiostatic control of the electrode potential. Potentials were measured and are quoted with respect to a calomel reference electrode saturated with sodium chloride, SSCE.

Temperature dependences of formal potentials were evaluated from cyclic voltammograms recorded in a nonisothermal cell having a thermally jacketed compartment for the working and auxiliary electrodes and a separate compartment for the reference electrode. The reference electrode was maintained at a fixed temperature. The principles and assumptions involved in the use of such cells have been examined in detail (9) and several recent experimental examples of their successful applications are available (10). Exposure of the polyelectrolyte coatings to solutions at $50^{\circ} \mathrm{C}$ caused the measured formal potentials of incorporated redox couples to drift slightly before new stable potentials resulted. We believe this behavior is the result of reproducible structural changes in the coatings. For this reason, the temperature dependences of formal potentials were measured with coatings that had been exposed to a solution at $50^{\circ} \mathrm{C}$ long enough for the cyclic voltammetric response to stabilize (ca. $30 \mathrm{~min}$ ). Thereafter, reproducible peak potentials were obtained at all temperatures.

\section{Results}

Cyclic voltammograms for the $\mathrm{Ru}\left(\mathrm{NH}_{3}\right)_{6}{ }^{3+/ 2+}$ couple at a graphite electrode coated with the carboxylate polyelectrolyte, II, are shown in Fig. 1. The effects of changes in scan rate on the response are the subject of Fig. 1a, while $1 \mathrm{~b}$ is concerned with the effects of changes in the coating thickness at a fixed scan rate. With thinner coatings or lower scan rates, the voltammograms exhibit two peaks. These are more clearly separated in the anodic half of the voltammograms.
The anodic peak at $-0.15 \mathrm{~V}$ is quite close to the corresponding peak obtained at an uncoated electrode, and it is this peak that disappears when the electrode used to record the voltammograms in Fig. 1 is transferred to a pure supporting electrolyte solution. Similar behavior was reported earlier for the voltammetry of $\mathrm{Ru}\left(\mathrm{NH}_{3}\right)_{6}{ }^{3+/ 2+}$ at electrodes coated with polyvinylsulfate (1). The peak that is present only in solutions containing $\mathrm{Ru}\left(\mathrm{NH}_{3}\right)_{6}{ }^{3+/ 2+}$ is believed to arise from the diffusive penetration of the polymer coating by the complex so that it is reduced and reoxidized directly at the electrode surface. That the peak does not arise from reaction at bare patches of the electrode exposed by imperfections in the coating was indicated by tests of coated electrodes with nonincorporating anions, such as $\mathrm{Fe}(\mathrm{CN})_{6}{ }^{4-}$, which exhibited much smaller peak currents and much greater peak potential separations at coated than at bare electrodes. In any case, the present study was devoted to comparisons between the voltammetric responses of redox couples at bare electrodes and those taken after their incorporation into coatings on electrodes which are subsequently transferred to a pure supporting electrolyte solution. Thus, the second peak evident in Fig. 1 presented no problems.

In Fig. 2 the cyclic voltammogram for $\mathrm{Ru}\left(\mathrm{NH}_{3}\right)_{6}{ }^{3+/ 2+}$ at a bare graphite electrode is compared with that for the same couple incorporated in a coating of the carboxylate polyelectrolyte, II. The large difference in the average of anodic and cathodic peak potentials (i.e., the formal potentials) of the couple in the two cases is evident. This difference in formal potentials should reflect the difference in the strength of the binding of each half of the redox couple to the polyelectrolyte coating. For example, if $[\mathrm{O}]_{\mathrm{s}} /[\mathrm{R}]_{\mathrm{s}}$ and $[\mathrm{O}]_{\mathrm{p}} /[\mathrm{R}]_{\mathrm{p}}$ are the equilibrium ratios of the concentrations of the oxidized and reduced forms of a couple in the solution (s) and polyelectrolyte (p) phases, respectively, the difference in the formal potentials observed in the two phases should be given by Eq. [1]

$$
E_{\mathrm{p}}^{\mathrm{f}}-E_{\mathrm{s}}^{\mathrm{f}}=\frac{R T}{\mathbf{F}}\left(\ln \frac{[\mathrm{O}]_{\mathrm{s}}}{[R]_{\mathrm{s}}}-\ln \frac{[\mathrm{O}]_{\mathrm{p}}}{[R]_{\mathrm{p}}}\right)
$$

Experimental values of $E_{\mathrm{p}}{ }^{\mathrm{f}}$ and $E_{\mathrm{s}} \mathrm{f}$ were obtained from the average of the peak potentials of voltammograms, such as those in Fig. 2. The voltammograms obtained
Fig. 1. Steady-state cyclic voltammograms for $1.0 \mathrm{mM}$ $\mathrm{Ru}\left(\mathrm{NH}_{3}\right)_{6}{ }^{3+}$ solution at a graphite electrode coated with polyelectrolyte II. Supporting electrolyte: $0.2 \mathrm{M} \mathrm{KCl}$ at $\mathrm{pH} 5.5$. (A) Coating contained $2.1 \times$ $10^{-7} \mathrm{~mol} \mathrm{~cm}^{-2}$ of carboxylate groups. Scan rate: $10,20,50 \mathrm{mV}$ $\mathrm{s}^{-1}$. (B) Scan rate: $100 \mathrm{mV} \mathrm{s}^{-1}$. Coatings contained $4.2,8.4$, and $21 \times 10^{-8} \mathrm{~mol} \mathrm{~cm}^{-2}$ of carboxylate groups.

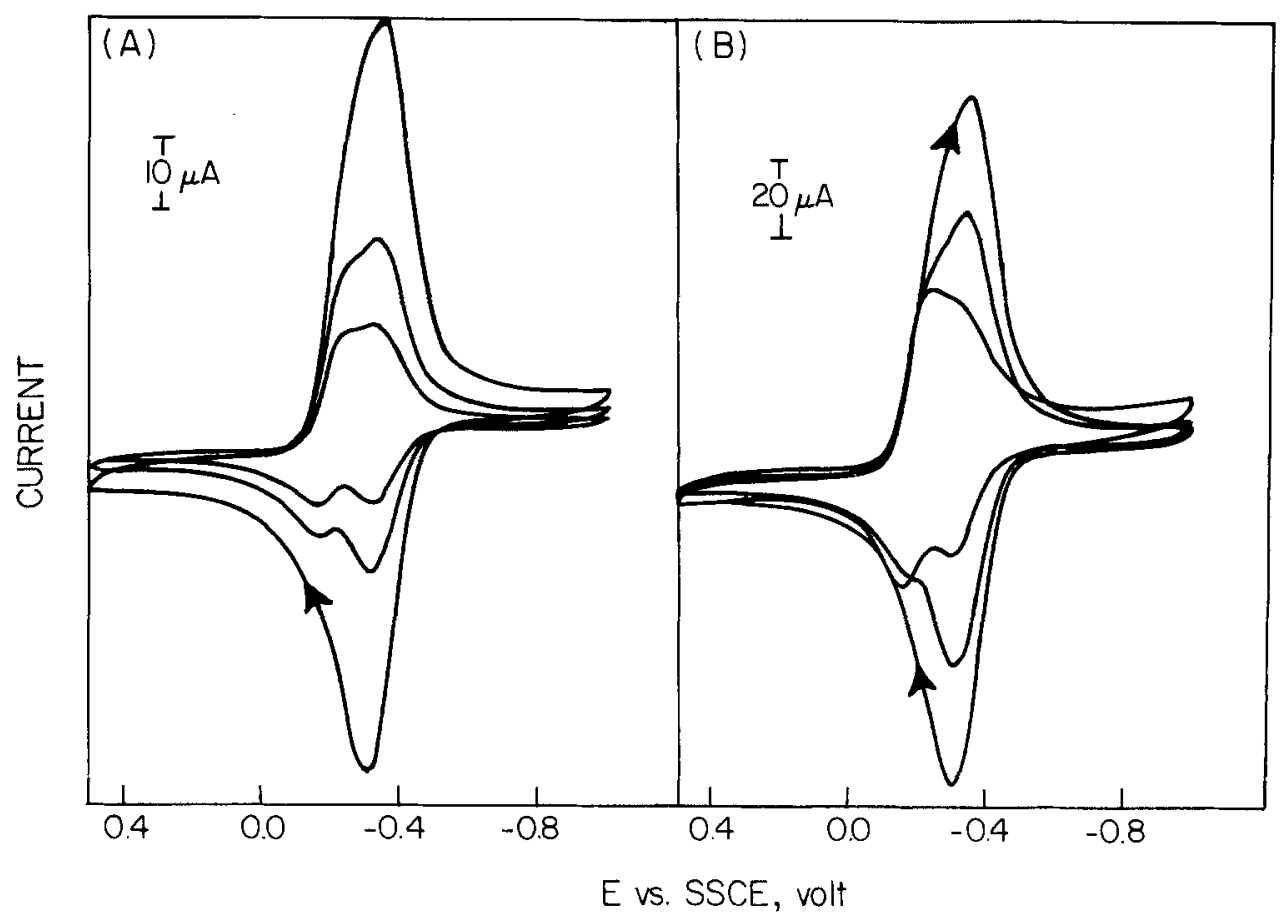




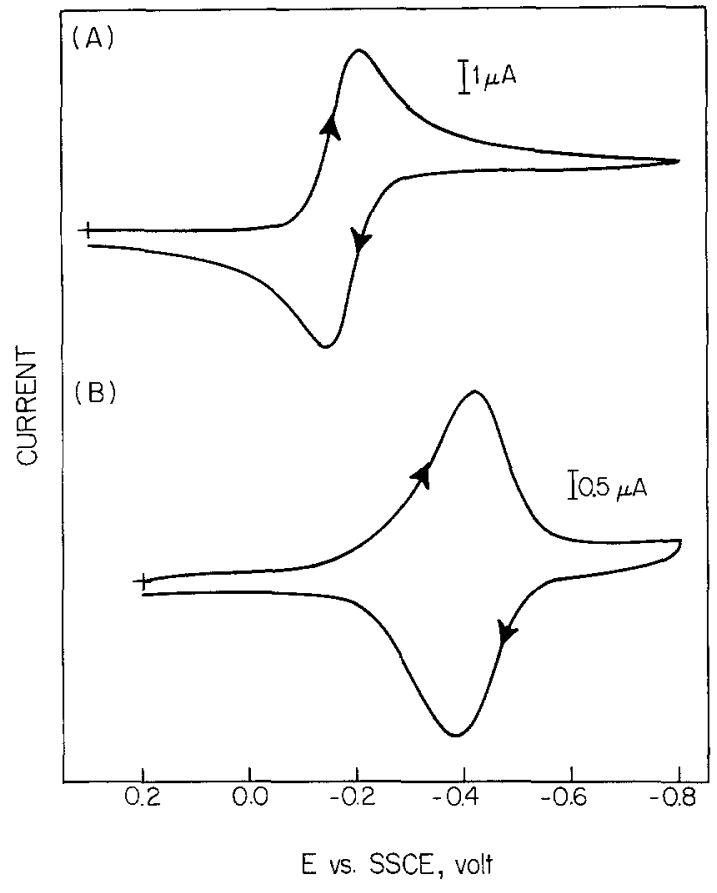

Fig. 2. (A) Cyclic voltammograms for $0.5 \mathrm{mM} \mathrm{Ru}\left(\mathrm{NH}_{3}\right)_{6}{ }^{3+}$ ot a bare graphite electrode. (B) Repeat after the electrode was coated with polyelectrolyte II $\left(8.4 \times 10^{-8} \mathrm{~mol} \mathrm{~cm}^{-2}\right.$ of carboxylate groups), soaked in the $\mathrm{Ru}\left(\mathrm{NH}_{3}\right)_{6}{ }^{3+}$ solution for 5 min and transferred to pure supporting electrolyte $\left(0.02 \mathrm{M} \mathrm{CH} \mathrm{CH}_{3} \mathrm{COONa}\right.$ of $\mathrm{pH}$ 5.5). Scan rote: $5 \mathrm{mV} \mathrm{s}^{-1}$ for both curves.

with the polyelectrolyte coatings were recorded at scan rates sufficiently small $\left(<5 \mathrm{mV} \mathrm{s}^{-1}\right)$ so that all of incorporated complex was reduced or oxidized during each half-cycle. The peak currents were proportional to scan rate, as expected under these conditions (11), and the formal potential was taken as the simple average of the peak potentials, which were typically separated by 10 to $30 \mathrm{mV}$ by residual ohmic potentials present in the cell and coating. At bare electrodes, the peak potentials were usually separated by $60-70 \mathrm{mV}$, as expected (12). The formal potential $\left(E_{\mathrm{s}}^{\mathrm{f}}\right)$ was obtained from the average of the peak potentials corrected for the difference in the solution diffusion coefficients of the two halves of the redox couple (12). This correction typically amounted to 1 to $2 \mathrm{mV}$.

The open-circuit equilibrium potential assumed by bare (or coated) electrodes in solutions containing both $\mathrm{O}$ and $\mathrm{R}$ is given by

$$
E_{\mathrm{eq}}=E_{\mathrm{s}} \mathrm{f}-\frac{R T}{\mathrm{~F}} \ln \frac{[\mathrm{R}]_{\mathrm{s}}}{[\mathrm{O}]_{\mathrm{s}}}
$$

Thus, Eq. [1] can be rewritten as

$$
E_{\mathrm{p}} \mathbf{f}=E_{\text {eq }}+\frac{R T}{\mathbf{F}} \ln \frac{[\mathrm{R}]_{\mathrm{p}}}{[\mathrm{O}]_{\mathrm{p}}}
$$

where $E_{\text {eq }}$ is the equilibrium potential of the coated (or bare) electrode in an incorporation solution which leads to the concentration ratio $[\mathrm{R}]_{\mathrm{p}} /[\mathrm{O}]_{\mathrm{p}}$ in the polyelectrolyte phase. Thus, to test Eq. [1], coated electrodes were equilibrated in incorporation solutions containing various ratios of the oxidized to reduced form of the redox couple. The formal potentials of the redox couple in the coating $\left(E_{\mathrm{p}} \mathrm{f}\right)$ were then compared with the sum $E_{\text {eq }}+R T / F \ln [R]_{\mathrm{p}} /[\mathrm{O}]_{\mathrm{p}}$ calculated from the observed values of $E_{\mathrm{eq}}$ and the measured concentrations of $R$ and $O$ in the polyelectrolyte phase. The latter were determined chronopotentiometrically (8) after the equilibrated electrode was transferred to a pure supporting electrolyte solution. The constant current densities (i) utilized in the chronopotentiometric measurements were kept small enough to be sure that all of the incorporated reactant in the coatings had been oxidized or reduced at the transition time $(\tau)$, so that the quantity of reactant could be calculated as $i \tau / n \mathbf{F}$.

At the transition time, a constant current in the opposite direction was passed through the coating until a second transition corresponding to the sum of the oxidized and reduced reactant initially present in the coatings resulted. Thus, if the first transition time $\left(\tau_{1}\right)$ was obtained with an anodic current $\left(i_{1}\right)$, and the second, $\left(\tau_{2}\right)$ resulted from a subsequent cathodic current $\left(i_{2}\right)$

$$
\frac{[\mathrm{O}]_{\mathrm{p}}}{[\mathrm{R}]_{\mathrm{p}}}=\frac{i_{2} \tau_{2}-i_{1} \tau_{1}}{i_{1} \tau_{1}}
$$

Figure 3 shows two representative chronopotentiograms for coatings in which the $\mathrm{Ru}\left(\mathrm{NH}_{3}\right)_{6}{ }^{3+/ 2+}$ or Os (bpy) $3^{3+12+}$ redox couples had been incorporated. Table I summarizes the results of a series of such experiments with three redox couples to test whether Eq. [1] and [3] provide an adequate description of the behavior of the coated electrodes. The agreement between the calculated and observed potentials in the last two columns of Table $I$ is, in most cases, within the experimental precision of $\pm 5 \mathrm{mV}$, so that Eq. [1] and [3] appear to be obeyed over a reasonably wide range of $\left[R 1_{p} /[O]_{p}\right.$ ratios. Thus, it may be concluded that the difference in measured formal potentials of redox couples in solution and incorporated within poly-
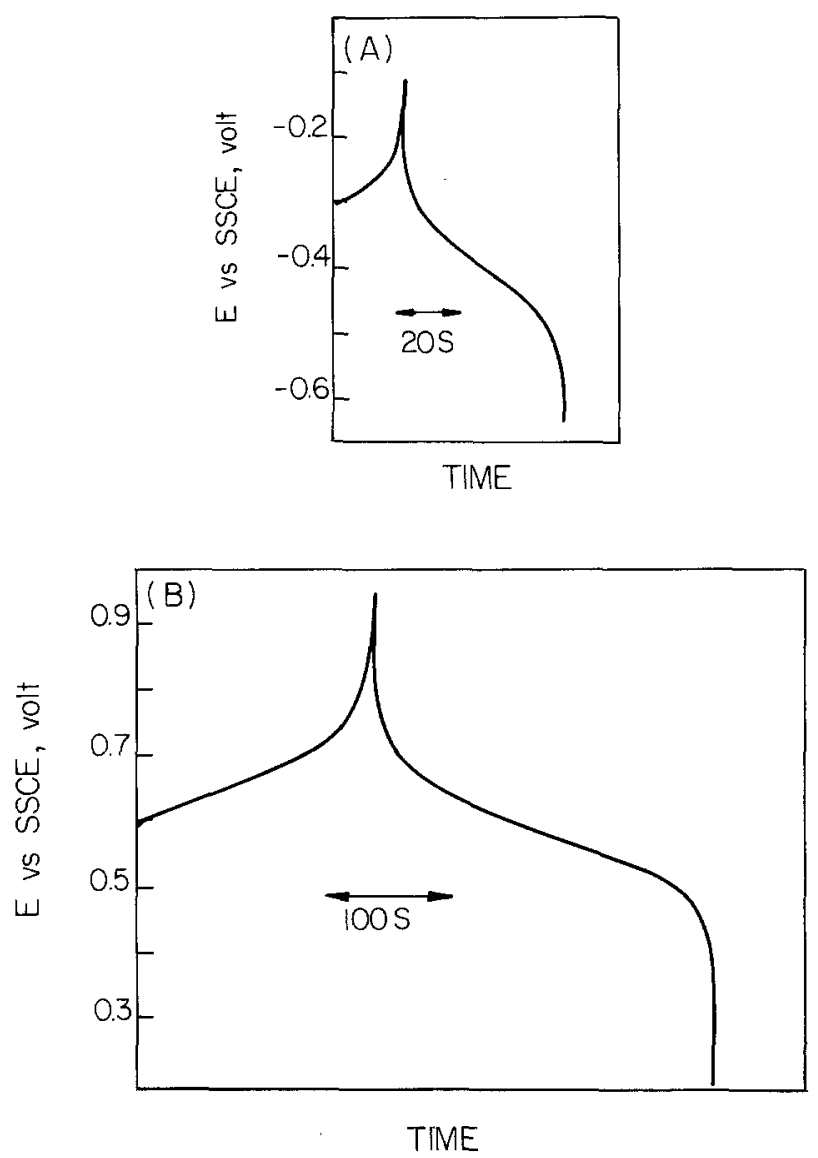

Fig. 3. Chronopotentiograms for the $\mathrm{Ru}\left(\mathrm{NH}_{3}\right)_{6}{ }^{3+/ 2+}$ and $\mathrm{O}_{\mathrm{s}}(\mathrm{bpy}) 3^{3+/ 2+}$ couples in coatings of polyelectrolyte II. (A) Electrode coated with $2.1 \times 10^{-7} \mathrm{~mol} \mathrm{~cm}^{-2}$ of carboxylate group equilibrated with a solution containing $\mathrm{Ru}\left(\mathrm{NH}_{3}\right)_{6}{ }^{3+}$ and $\mathrm{Ru}\left(\mathrm{NH}_{3}\right)_{6}{ }^{2+}\left(E_{\text {eq }}=312 \mathrm{mV} ;\left[\mathrm{Ru}\left(\mathrm{NH}_{3}\right)_{6}{ }^{3+}\right]+\left[\mathrm{Ru}\left(\mathrm{NH}_{3}\right)_{6}{ }^{2+}\right]\right.$ $=1.0 \mathrm{mM}$ ) before transfer to pure supporting electrolyte solution (0.02M CH $\mathrm{COONa}_{3}$ at $\mathrm{pH} 5.5$ ). Constant current density $=1.15$ $\mu \mathrm{A} \mathrm{cm} \mathrm{cm}^{-2}$ for oxidation of $\mathrm{Ru}(\mathrm{II})$ and $23.0 \mu \mathrm{A} \mathrm{cm}-2$ for reduction of $\mathrm{Ru}(\mathrm{III})$. (B) Electrode coated with $8.4 \times 10^{-8} \mathrm{~mol} \mathrm{~cm}^{-2}$ of carboxylate groups equilibrated with a solution of $\mathrm{O}_{5}(\mathrm{bpy})_{3} 3^{3+}$ and Os $(b p y)_{3}{ }^{2+}\left(E_{\text {eq }}=602 \mathrm{mV} ;\left[\mathrm{Os}_{\mathrm{s}}(\mathrm{bpy})_{3}{ }^{3+}\right]+\left[\mathrm{Os}(\mathrm{bpy})_{3}{ }^{2+}\right]=\right.$ $0.5 \mathrm{mM}$ ). Constant current density $=2.87 \mu \mathrm{A} \mathrm{cm}-2$ throughout. 
Table I. Calculated and observed shifts in formal potentials of redox couples incorporated in coating of polyelectrolyte IIa

\begin{tabular}{|c|c|c|c|c|}
\hline Redox couple & $\begin{array}{l}E_{\mathrm{e} 4} \mathrm{~b} \\
(\mathrm{mV})\end{array}$ & $\frac{[R]_{p} c}{[O]_{p}}$ & $+\frac{R T}{F} \ln \left(\frac{[R]_{p}}{[O]_{p}}\right)$ & $\begin{array}{l}E_{p^{f d}} \\
(m V)\end{array}$ \\
\hline Os(bpy) $\mathrm{a}^{3+/ j+}$ & $\begin{array}{r}-312.0 \\
-60.0 \\
-43.0 \\
-40.0 \\
-37.0 \\
-24.0 \\
-19.0 \\
0.0 \\
+10.0 \\
602.0 \\
605.0\end{array}$ & $\begin{array}{l}0.024 \\
5.000 \\
2.570 \\
2.450 \\
1.800 \\
0.900 \\
0.900 \\
0.630 \\
0.420 \\
2.380 \\
2.210\end{array}$ & $\begin{array}{r}-408.0 \\
-20.0 \\
-20.0 \\
-17.0 \\
-22.0 \\
-23.0 \\
-20.0 \\
-12.0 \\
-12.0 \\
624.0 \\
625.0\end{array}$ & $\begin{array}{r}-402.0 \\
-21.0 \\
-21.0 \\
-21.0 \\
-21.0 \\
-21.0 \\
-21.0 \\
-21.0 \\
-21.0 \\
609.0 \\
609.0\end{array}$ \\
\hline
\end{tabular}

a. The coatings contained $8.4 \times 10^{-8} \mathrm{~mol} \mathrm{~cm}^{-2}$ of carboxyl groups in every case, except $\mathrm{Ru}\left(\mathrm{NH}_{3}\right)_{6^{3+}+2+}$, where the coating contained

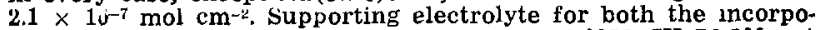
ration and chronopotentiometric assay was $0.02 \mathrm{M} \mathrm{CH}_{3} \mathrm{COONa}$ at

pH 5.5. trode in the solution from where the incorporation was carried out.

. Ratio of the reduced to the oxidized form of the redox couple in the polyelectrolyte phase. Determined by chronopotentiometric assay using Eq. [4].

d Formal potential (vs. SSCE) of the redox couple within the polyelectrolyte coating.

- isn = isonicotinamide.

electrolyte II reliably reflects the difference between the free energy changes associated with the incorporation of the two halves of the redox couple by the polyelectrolyte.

Effect of changes in ionic strength.-The incorporation of cationic redox couples by polyelectrolyte II is an ion exchange process involving displacement of equivalent quantities of the unipositive counterions initially present in the polyelectrolyte. For this reason, the extent of incorporation for each half of a redox couple would be expected to exhibit a dependence on the ionic strength of the incorporation solution. This expectation was tested by measuring the differences between the formal potentials of several redox couples in solution and within the polyelectrolyte coating as a function of ionic strength. The results, summarized in Table II, show that the difference in formal potentials measured inside and outside of the polyelectrolyte coatings is strongly dependent on ionic strength and on the nature of the redox couple.

Temperature dependence of the formal potentialTo obtain additional insight into the factors responsible

Table II. Ionic strength dependence of the difference between redox formal potentials in solution and within coatings of polyelectrolyte $\mathrm{II}^{\mathrm{a}}$

\begin{tabular}{|c|c|c|c|c|}
\hline Redox couple & $\begin{array}{l}\text { Supporting } \\
\text { electrolyte } \\
\text { conc }^{b} M\end{array}$ & $\begin{array}{l}E_{\mathbf{g}} \mathbf{p}^{\circ} \\
\mathrm{mV} \\
\text { vs. SSCE }\end{array}$ & $\begin{array}{c}E_{p} t d \\
\text { mV } \\
\text { vs. SSCE }\end{array}$ & $\begin{array}{c}E_{\mathrm{p}^{l}}-E_{\mathrm{s}}{ }^{\prime} \\
=\Delta E^{\mathrm{t}} \\
\mathrm{mV}\end{array}$ \\
\hline $\mathrm{Ru}\left(\mathrm{NH}_{3}\right) \mathrm{e}^{3+42+}$ & $\begin{array}{l}0.02 \\
0.20 \\
2.00\end{array}$ & $\begin{array}{l}-169.0 \\
-185.0 \\
-220.0\end{array}$ & $\begin{array}{l}-402.0 \\
-347.0 \\
-290.0\end{array}$ & $\begin{array}{r}-233.0 \\
-162.0 \\
-70.0\end{array}$ \\
\hline $\mathrm{Ru}\left(\mathrm{NH}_{3}\right)_{5} \mathrm{isn}^{3+/ E_{+}}$ & 0.02 & 158.0 & -21.0 & -179.0 \\
\hline$O s(b p y) s^{3+/ 2+}$ & $\begin{array}{l}0.02 \\
0.20 \\
2.00\end{array}$ & $\begin{array}{l}619.0 \\
608.0 \\
607.0\end{array}$ & $\begin{array}{l}609.0 \\
632.0 \\
683.0\end{array}$ & $\begin{array}{r}-10.0 \\
24.0 \\
76.0\end{array}$ \\
\hline $\begin{array}{l}\mathrm{CpFeCpCH_{2 } \mathrm { N }} \\
\left(\mathrm{CH}_{3}\right) \mathrm{s}^{2+1+e}\end{array}$ & 0.20 & 388.0 & 381.0 & -7.0 \\
\hline
\end{tabular}

a All coatings contained $8.4 \times 10^{-8} \mathrm{~mol} \mathrm{~cm}-2$ of carboxyl groups b The supporting electrolyte was $\mathrm{CH}_{3} \mathrm{COONa}$, and all solutions were adjusted to $\mathrm{pH} \mathbf{5 . 5}$.

c Formal potential of the couple in homogeneous solution, obtained from the average of cyclic voltammetric peak potentials tained from the average of cyclic voltammetric peak poted for differences in diffusion coefficients (12).

d Formal potential of the redox couple with the polyelectrolyte coating as obtained from cyclic voltammograms recorded at low coating as scan rate.

- $\mathrm{C}_{\mathrm{p}}=$ cyclopentadienide. for the opposite shifts in formal potential of the

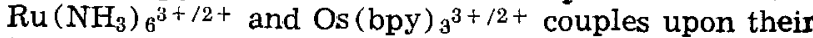
incorporation in the polyelectrolyte coatings, the temperature dependences of the formal potentials of the two couples were measured within the coatings and at a bare electrode. The results, plotted in Fig. 4, show that increases in temperature cause the formal potentials for both couples to shift to more negative values within coatings of polyelectrolyte II but in the opposite direction in homogeneous solutions.

The formalism of Weaver et al. (9) can be used to evaluate half-reaction entropies for redox couples $\left(\Delta S_{\mathrm{rc}}{ }^{\circ}\right)$ from the slopes of the lines in Fig. 4. The resulting values are listed in Table III. For $\mathrm{Ru}\left(\mathrm{NH}_{3}\right)_{6}{ }^{3+} / 2+$, the value of $\Delta S_{\mathrm{rc}}{ }^{\circ}$ at the bare electrode agrees well with that reported by Weaver et al. (9), and the value for Os (bpy) $3^{3+/ 2+}$ is not far from their value for the isostructural $\mathrm{Fe}$ (bpy) $3^{3+/ 2+}$ couple (9).

The difference between the values of $\Delta S_{\mathrm{rc}}{ }^{\circ}$ at bare and coated electrodes $\left(\Delta \Delta S_{\mathrm{rc}}{ }^{\circ}\right)$ (Table III) represents the entropy change associated with an overall reaction such as

$$
\begin{aligned}
\left(\sim \sim \mathrm{A}^{-}\right)_{2^{---}} \mathrm{Ru}\left(\mathrm{NH}_{3}\right)_{6} 6^{+}+\sim \sim \mathrm{A}^{-}---\mathrm{Na}^{+} \\
+\mathrm{Ru}\left(\mathrm{NH}_{3}\right)_{6^{3+}}{ }_{(\mathrm{aq})} \rightarrow\left(\sim \sim \mathrm{A}^{-}\right)_{3^{---}} \rightarrow \mathrm{Ru}_{\left(\mathrm{NH}_{3}\right)_{6}{ }^{3+}} \\
+\mathrm{Na}_{(\mathrm{aq})^{+}}+\mathrm{Ru}\left(\mathrm{NH}_{3}\right)_{6}{ }^{2+}{ }_{(\mathrm{aq})}
\end{aligned}
$$

where $\sim A^{-}$represents one of the anionic fixed charge groups of the polyelectrolyte, and (aq) denotes the hydrated ion in the bulk of the solution. The ionic aggregates inside the polyelectrolyte, denoted by $\left(\sim \sim \mathrm{A}^{-}\right)_{n^{--}} \mathrm{Ru}\left(\mathrm{NH}_{3}\right)_{6^{n+}}{ }^{n}$, may also be hydrated to an extent that is great enough to affect both their entropies and enthalpies significantly.

The positive values of $\Delta \Delta S_{\mathrm{rc}}{ }^{\circ}$ in Table III show that the substitution for one incorporated cationic complex of its redox partner with the higher charge leads to a net increase in entropy in each case. The corresponding enthalpic differences, $\Delta \Delta H_{298^{\circ}}$, are positive, strikingly so in the case of polyelectrolyte II. Thus, the preferential incorporation of the more highly charged cations is driven by the large release of entropy.

$p H$ dependence of the incorporation.-The effective $p \mathrm{~K}_{\mathrm{a}}$ of the carboxylic acid groups in polyelectrolyte II can be inspected by measuring tne ertect of $p H$ on the incorporation of cations by the polyelectrolyte. Experiments of this type were performed by exposing a coating of polyelectrolyte II to a solution of $\mathrm{Ru}\left(\mathrm{NH}_{3}\right)_{0}^{3+}$ which was adjusted to $p H$ values between 1.5 and 5.5 . After the incorporation equilibrium had been attained (30 $\mathrm{min}$ of exposure proved adequate), the coated electrode was transterred to a pure supporting electrolyte solution at the same $p H$, and the amount of $\mathrm{Ru}\left(\mathrm{NH}_{3}\right)_{6}{ }^{3}+$ retained by the coating was determined by stepping the electrode potential to $-0.6 \mathrm{~V}$ and measuring the total cathodic charge that passed before the current decreased to background levels. The results are shown in Fig. 5. The $p H$ at which the incorporation reaches one-half of its maximum value [only ca. $36 \%$ of the total carboxylate groups in the coating bound $\mathrm{Ru}\left(\mathrm{NH}_{3}\right)_{6}{ }^{3+}$ cations that were in electronic contact with the electrode] is 2.2. This value is close to the $p K_{8}$ of 1.9 measured more directly for a similar perfluorocarboxylate polyelectrolyte (13). However, the shape of the plot in Fig. 5 does not match that of a typical pH titration curve. This is presumably because of interactions among the high concentration of carboxylate groups within the polyelectrolyte. Similar behavior was reported recently in coatings of protonated polyvinylpyridine (14). Thus, it is not accurate to identify the $\mathrm{pH}$ corresponding to half-maximum incorporation in Fig. 5 with a single $p K_{\mathrm{a}}$ of the functional group. The "effective $p K_{\mathrm{a}}$ " (14) varies with the degree of protonation and with the ionic strength. Nevertheless, it is clear that at $p H$ values as low as 1 , protons compete 


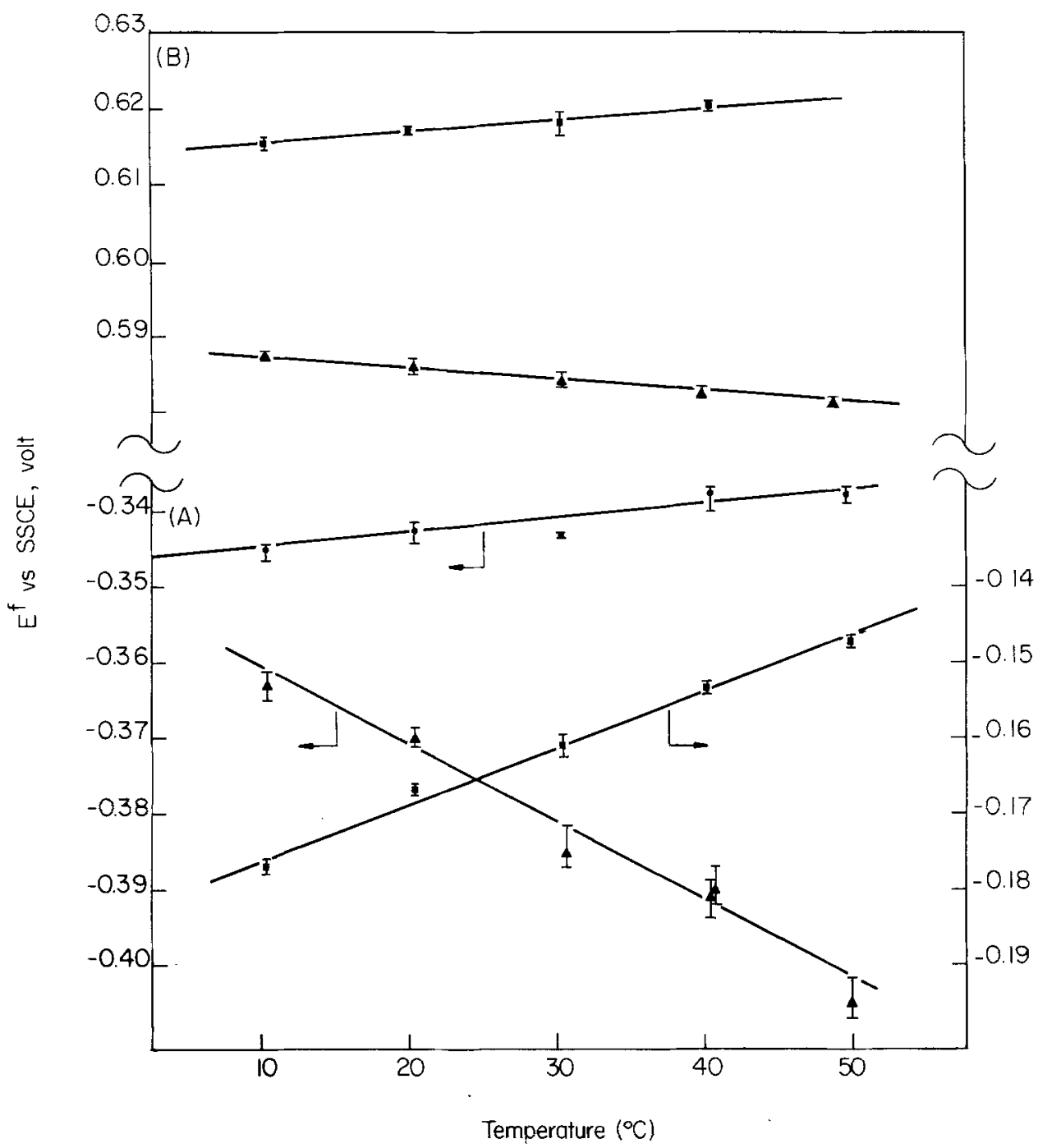

Fig. 4. Temperature dependences of the formal potentials of the $\mathrm{Ru}\left(\mathrm{NH}_{3}\right)_{6}{ }^{3+/ 2+}$ and Os(bpy $)_{3} 3+12+$ couples. (A) Ru$\left(\mathrm{NH}_{3}\right)_{6}{ }^{3+/ 2+}$. (B) Os(bpy $)^{3+/ 2+}$. (a) Bare electrode. (A) Electrode coated with polyelectrolyte (II). (•) Electrode coated with Nafion. Supporting electrolyte: $0.02 \mathrm{M} \quad \mathrm{CH}_{3} \mathrm{COONa}$ at pH 5.5.

quite successfully with $\mathrm{Ru}\left(\mathrm{NH}_{3}\right)_{8}^{3+}$ ions for counterionic sites within the polyelectrolyte.

\section{Discussion}

The combination of data in Tables I and II shows that the equilibrium constants governing the incorporation of cations by coatings of polyelectrolyte II control the changes in the formal potentials of redox couples extracted into the coatings. The trends in the values of $E_{\mathrm{p}}^{\mathrm{f}}-E_{\mathrm{s}}^{\mathrm{f}}\left(=\Delta E^{\mathrm{f}}\right)$ in Table II demonstrate that the relative equilibrium binding constants for two halves of a redox couple are not determined solely by the magnitudes of their positive charges. Thus, the $\mathrm{Ru}\left(\mathrm{NH}_{3}\right)_{6}{ }^{3+/ 2+}$ and Os(bpy) $3^{3+/ 2+}$ couples involve the same pair of charge types but, at ionic strengths above ca. $0.05 M$, the formal potentials of the two couples are shifted in opposite directions by incorporation.

The additional factor affecting the incorporation equilibria seems likely to be hydrophobic interactions between the large fluorocarbon component of the polyelectrolyte coating and the incorporating cations. Previously cited evidence of such hydrophobic interactions has included the blue shift in the fluorescence of $\mathrm{Ru}$ (bpy) $3^{2+}$ incorporated in Nafion membranes compared with the red shift observed with other, less hydrophobic, polyelectrolytes (15). In adidition, the much smaller diffusion coefficients within Nafion coatings of cations surrounded by hydrophobic ligands has been interpreted in terms of a strong interaction between the diffusing ions and the hydrophobic fluorocarbon portions of the interior of the polyelectrolyte (16).

The trends evident in the data of Table II can be rationalized in terms of the relative importance of hydrophobic and electrostatic interactions between the incorporated cations and the polyelectrolyte. For example, at an ionic strength of $0.2 M, \Delta E^{\mathrm{f}}$ is positive for $\mathrm{Os}$ (bpy) ${ }_{3}^{3+/ 2+}$, near zero for $\mathrm{CpFeCpCH} 2 \mathrm{~N}\left(\mathrm{CH}_{3}\right)_{3}{ }^{2+1+}$ and negative for $\mathrm{Ru}\left(\mathrm{NH}_{3}\right)_{6}{ }^{3+/ 2+}$. The less highly

Table III. Differences in half-reaction entropies and enthalpies for the $\mathrm{Ru}\left(\mathrm{NH}_{3}\right)_{6}{ }^{3+/ 2+}$ and $\mathrm{Os}(\mathrm{bpy})_{3}{ }^{3+/ 2+}$ couples in coatings of Nafion and polyelectrolyte IIa

\begin{tabular}{|c|c|c|c|c|c|}
\hline Redox couple & Electrode coating & $\begin{array}{c}\Delta S_{\mathrm{rc}}{ }^{\circ}{ }^{b} \\
\mathrm{cal} / \mathrm{K}\end{array}$ & $\begin{array}{c}\Delta \Delta S_{\mathrm{rr}}{ }^{\circ} \mathrm{c} \\
\mathrm{cal} / \mathrm{K} \cdot \mathrm{mol}\end{array}$ & $\underset{\text { kcal mol-1 }}{\Delta \Delta H_{290^{\circ}}}$ & $\underset{\text { kcal mol-3 }}{\Delta \Delta G_{23 s^{\circ}}}$ \\
\hline $\mathrm{Ru}\left(\mathrm{NH}_{3}\right) 0^{3+/ 2+}$ & $\begin{array}{l}\text { Bare } \\
\text { Nafion } \\
\text { II }\end{array}$ & $\begin{array}{r}+17.1(0.99) \\
+\quad 4.6(0.90) \\
-23.5(0.98)\end{array}$ & $\begin{array}{l}+12.5 \\
+40.6\end{array}$ & $\begin{array}{l}-0.36 \\
+7.22\end{array}$ & $\begin{array}{l}-4.09 \\
-4.88\end{array}$ \\
\hline Os(bpy) $\mathbf{s}^{3+/ 2+}$ & BI & $\begin{array}{l}+3.5(0.90) \\
-3.8(0.95)\end{array}$ & +7.30 & +1.42 & -0.75 \\
\hline
\end{tabular}

Supporting electrolyte: $0.02 \mathrm{M} \mathrm{CH}_{3} \mathrm{COONa}$ at $\mathrm{pH} 5.5$.

b The entropy change for the half-reaction: $\mathrm{M}^{3+}+e^{-} \rightleftarrows \mathrm{M}^{2+}$. Calculated from the slopes of the lines in Fig. 4. Linear correlation

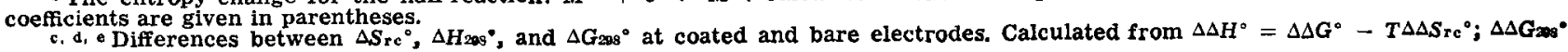
$=-n F \Delta E^{r}$. 


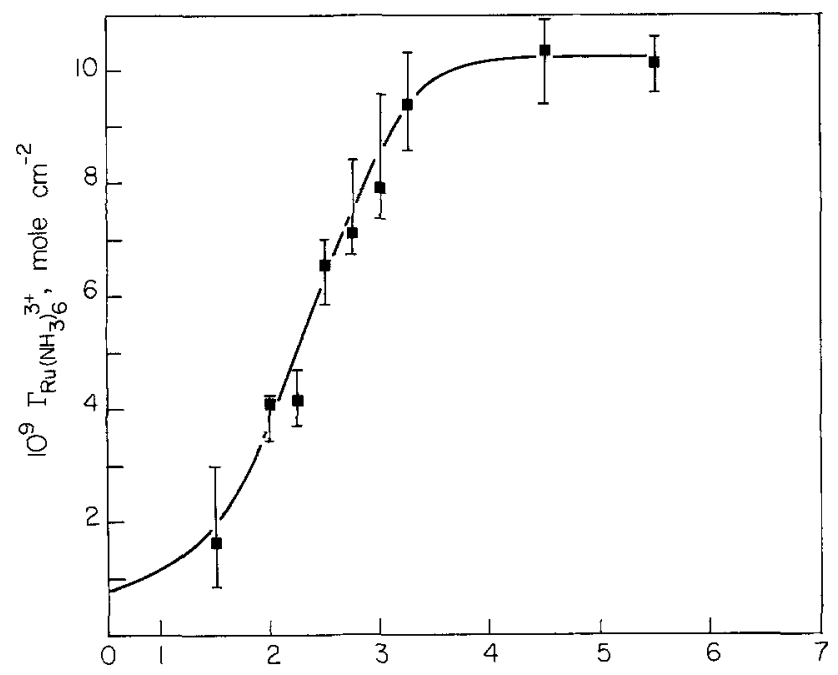

$\mathrm{pH}$

Fig. 5. Incorporation of $\mathrm{Ru}\left(\mathrm{NH}_{3}\right)_{6}{ }^{3+}$ by polyelectrolyte II as a function of $p \mathrm{H}$. Electrode coating contained $8.4 \times 10^{-8} \mathrm{~mol} \mathrm{~cm}^{-2}$ of carboxylate groups. Electrode was equilibrated for $30 \mathrm{~min}$ with a $5 \mathrm{mM}$ solution of $\mathrm{Ru}\left(\mathrm{NH}_{3}\right)_{6}{ }^{3+}$ at each $\mathrm{pH}$ before transfer to pure supporting electrolyte for measurement of the quantity incorporated. Supporting electrolyte: $\mathrm{pH} \supseteq$ 4.5: acetate buffer; $2.25 \leq p H \leq 3.25$ : phosphate buffer; $p \mathrm{H} \leq 2: \mathrm{HCl}+\mathrm{NaCl}$. The ionic strength was maintained at $0.2 \mathrm{M}$.

charged (i.e., reduced) form of each couple would be more hydrophobic and therefore would be expected to be preferentially stabilized by hydrophobic interaction compared with its more highly charged (oxidized) partner. By contrast, purely electrostatic stabilizing interactions would act in the opposite direction. Thus, the values of $\Delta E^{\mathrm{f}}$ for the three couples listed above indicate the dominance of hydrophobic interactions for $\mathrm{Os}(\mathrm{bpy})^{3+/ 2+}$ and hydrophilic interactions for

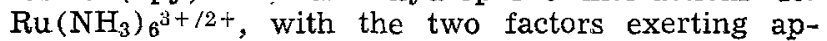
proximately equal and opposite influences in the case of $\mathrm{CpFeCpCH}_{2} \mathrm{~N}\left(\mathrm{CH}_{3}\right)_{3}{ }^{2+1+}$. This seems chemically reasonable because the order of increasing hydrophobicity of the three redox couples is very likely to be $\mathrm{Os}(\mathrm{bpy})_{3}{ }^{3+12+}>\mathrm{CpFeCpCH}_{2} \mathrm{~N}\left(\mathrm{CH}_{3}\right)_{3}{ }^{2+1+}>$ $\mathrm{Ru}\left(\mathrm{NH}_{3}\right)_{6}^{3+/ 2+}$.

The effects of changes in ionic strength on the values of $\Delta E^{f}$ in Table II for the $\mathrm{Ru}\left(\mathrm{NH}_{3}\right)_{6}{ }^{3+/ 2+}$ and Os (bpy) $3^{3+/ 2+}$ couples can be understood on the same basis. Alterations in the intensity of hydrophobic interactions produced by changes in ionic strength are not likely to be as large as the expected (17) decreases in electrostatic interaction as the ionic strength increases. The latter changes can be substantial as the behavior of the Os (bpy) $3^{3+12+}$ couple indicates. In $2 M$ supporting electrolyte, $\Delta E^{\mathrm{I}}$ is most positive, pointing to the strongest hydrophobic stabilization, while in $0.02 \mathrm{M}$ solutions $\Delta E^{\mathrm{f}}$ becomes slightly negative, suggesting that under these conditions the strength of the electrostatic interaction has increased sufficiently to overcome the hydrophobic factors that act in the opposite direction. The much more hydrophilic $\mathrm{Ru}\left(\mathrm{NH}_{3}\right)_{5^{3}+12+}$ couple exhibits $\Delta E^{\mathrm{f}}$ values that reflect dominance by electrostatic interactions at all ionic strengths. The intensity of these interactions is evidently quite large for this couple, as indicated by the unusually large value of $\Delta E^{\mathrm{f}}$ in the $0.02 M$ electrolyte.

$\Delta E^{\mathrm{f}}$ was also measured for the $\mathrm{Ru}\left(\mathrm{NH}_{3}\right)_{6}{ }^{3+/ 2+}$ couple at $0.2 M$ ionic strength in Nafion coatings. The value observed was $-100 \mathrm{mV}$, compared with $-164 \mathrm{mV}$ for polyelectrolyte II under the same conditions. Similar differences exist between the strength of the binding of alkali cations by ion-exchange resins based on sulfonate and carboxylate groups (18). The behavioral difference has been ascribed to differences in the struc- ture of the primary hydration spheres of the cations induced by the two types of anionic binding groups (18). In the present case, where hydrophobic and electrostatic factors are also believed to influence the strength of cation binding, the difference in $\Delta E^{f}$ for Nafion and polyelectrolyte II for the $\mathrm{Ru}\left(\mathrm{NH}_{3}\right)_{6}{ }^{3+12+}$ couple may reflect a greater control by electrostatic binding in the latter coating.

The entropic control of the incorporation equilibria revealed in the data of Table III suggests a primary role for water molecules in the overall incorporation process. This accords with several previous studies of cation binding by polyanionic electrolytes (19), in which evidence was presented for the release of water molecules from both the charged binding sites and the hydration spheres of the bound cations. The large negative value of $\Delta S_{\mathrm{rc}}{ }^{\circ}$ for the $\mathrm{Ru}\left(\mathrm{NH}_{3}\right)_{6}{ }^{3+/ 2+}$ couple in polyelectrolyte II signals an unusual ionic and solvation environment for the couple in this polyelectrolyte. The binding of the $\mathrm{Ru}\left(\mathrm{NH}_{3}\right)_{6}{ }^{3+/ 2+}$ couple by Nafion produces much smaller value of $\Delta \Delta S_{\mathrm{rc}}{ }^{\circ}$ than for binding to the polycarboxylate, II. This may be a reflection of a higher charge denity on the fixed anionic sites in II compared with Nafion. This could produce tighter ion pairing with multiply charged cations within polyelectrolyte II and greater loss of water molecules from the outer coordination spheres of the incorporated complexes. Differences in the partial molar volumes of sulfonate and carboxylate bearing polyelectrolytes upon incorporation of cations were explained in similar terms by Tondre and Zana (19d).

The positive value of $\Delta \Delta H^{\circ}$ for incorporation of the $\mathrm{Ru}\left(\mathrm{NH}_{3}\right)_{6}{ }^{3+/ 2+}$ couple by polyelectrolyte II (Table III) represents the net result of a variety of coulombic and dipolar interactions whose individual contribution to the measured values of $\Delta \Delta H_{298^{\circ}}$ it would be extremely difficult to disentangle. However, it may be worth noting that the behavior we have observed is similar to that reported for the incorporation from aqueous solution of an organic sulfonate (8-anilino1-naphthalene sulfonate) by the hydrophobic portion of a block copolymer of polyethylene oxide and poly(2hydroxyethyl methacrylate) (20). The incorporation, which is free of direct electrostatic binding between fixed charge groups and the incorporating ions, is also governed by a positive entropy change that overcomes a corresponding increase in enthalpy. Differences in the ion-dipole interaction energies between the incorporating ion and water molecules inside and outside the polymer may make important contributions to the enthalpy changes in both this instance and the incorporation of the $\mathrm{Ru}\left(\mathrm{NH}_{3}\right)_{6}{ }^{3+/ 2+}$ couple by polyelectrolyte II. In any case, the point to be derived from the present study is that the factors governing the relative binding interactions of polyelectrolytes and complex ions can involve much more than the relative charge densities of the latter.

\section{Acknowledgments}

This work was supported by the U.S. Army Research Office. Dr. H. Zumbrunnen offered many helpful suggestions during early stages of this work. We thank Asahi Glass Company, Tokyo, for a sample of polyelectrolyte II.

Manuscript submitted May 20, 1983; revised manuscript received Sept. 23, 1983.

\section{REFERENCES}

1. N. Oyama, T. Shimomura. K. Shigehara, and F. C. Anson, $J$. Electroanal. Chem. Interfacial Electrochem., 112, 271 (1980).

2. K-N. Kuo and R. W. Murray, ibid., 131, 37 (1982).

3. H. Braun, W. Storck, and K. Doblhofer, This Journal, 130, 807 (1983)

4. D. A. Buttry and F. C. Anson, J. Am. Chem. Soc. 104,4824 (1982)

5. N. Oyama and F. C. Anson, ibid., 101, 3450 (1979). 
6. R. G. Gaunder and H. Taube, Inorg. Chem., 9, 2627 (1970)

7. C. Creutz, M. Chou, T. L. Netzel, M. Okumura, and N. J. Sutin, J. Am. Chem. Soc., 102, 1309 (1980).

8. A. J. Bard and L. R. Faulkner, "Electrochemical Methods," p. 536, John Wiley and Sons, Inc., New York (1980).

9. E. L. Yee, R. J. Cave, K. L. Guyer, P. D. Tyma, and M. J. Weaver, J. Am. Chem. Soc., 101, 1131 (1979).

10. (a) N. Sutin, M. J. Weaver, and E. L. Yee, Inorg. Chem., 19, 1096 (1980); (b) E. L. Yee and M. J. Weaver, ibid, 19, 1077 (1980); (c) M. J. Weaver and S. M. Nettles, ibid., 19, 1641 (1980); (d) S. Sahami and M. J. Weaver, J. Electroanal. Chem. Interfacial Electrochem., 122, 155, 171 (1981); (e) V. T. Taniguchi, W. R. Ellis, Jr., V. Cammarata, J. Webb, F. C. Anson, and H. B. Gray, Adv. Chem. Ser., 201, 51 (1982).

11. N. Oyama and F. C. Anson, This Journal, 127, 640 (1980).

12. A. J. Bard and L. R. Faulkner, "Electrochemical Methods," Chap. 6, John Wiley and Sons, New York $(1980)$.
13. Z. Twardowski, H. L. Yeager, and B. O'Dell, This Journal, 129, 328 (1982).

14. H. Zumbrunnen and F. C. Anson, J. Electroanal. Chem. Interfacial Electrochem., 152, 111 (1983)

15. P. C. Lee and D. Meisel, J. Am. Chem. Soc., 102, 5477 (1980).

16. D. A. Buttry and F. C. Anson, ibid., 105, 685 (1983).

17. F. G. Helfferich, "Ion Exchangers," Chap. 4, McGraw-Hill, New York (1962).

18. (a) H. Morawetz "Macromolecules in Solution," 2nd ed., p. 369, John Wiley and Sons, New York (1975); (b) L. Lazare, B. R. Sundheim, and H. P. Gregor, J. Phys, Chem., 60, 641 (1956); (c) I. Michalei and A. Katchalsky, J. Polym. Sci., 23, $683(1957)$; (d) F. Nelson and K. A. Kraus, J. Am. Chem. Soc., 80, 4154 (1958); (e) M. H. Gottlieb and H. P. Gregor, ibid., 76, 4639 (1954).

19. (a) G. E. Boyd and D. P. Wilson, Macromolecules, 15, 78 (1982); (b) M. Finaudo and M. Milas, ibid., 6, 879 (1973); (c) J. Hen and U. P. Strauss, J. Phys. Chem. 78, 1013 (1974); (d) C. Tondre and R. Zana, ibid., 76, 3451 (1972).

20. M. Ikemi, N. Odagiri, and I. Shinohara, Polymer J., 12, 777 (1980).

\title{
Measurements of the Steady-State Activation Overpotential of Chlorine Evolving Electrodes
}

\author{
I. V. Kadija \\ Olin Corporation, Metals Research Laboratories, New Haven, Connecticut 06511
}

\section{ABSTRACT}

Detailed measurements of interfacial concentration and concentration overpotential of chlorine evolving platinized platinum electrodes were performed in $4.9 \mathrm{M} \mathrm{NaCl}$, at $25^{\circ} \mathrm{C}$ and $1 \mathrm{~atm}$ chlorine or 1 atm nitrogen in the cell. Based on these and electrode polarization measurements, steady-state activation overpotential curves were obtained. The applied method enabled for the first time in this field, development of true steady-state activation overpotential curves. Our findings indicated that $30-40 \mathrm{mV} /$ decade slopes typically obtained in nitrogen atmosphere were essentially a sequence of quasi equilibria at the electrode interface. Also, micropolarization data obtained near the open circuit with chlorine atmosphere in the cell were found to be a concentration overpotential phenomenon. The true activation overpotential was found to become a significant part of the electrode polarization only after it exceeded several millivolts in chlorine saturated brine. In nitrogen saturated brine, where the open circuit was undefined, the activation overpotential became significant for polarizations that exceeded two decades of steady-state low current density polarization. In this case, the activation overpotential was observable as a departure from a $32 \mathrm{mV}$ /decade slope. The obtained activation overpotential curves can be used as a base for developing kinetic parameters, however, a considerably greater emphasis than in the past must be given to the corresponding interfacial conditions.

A steady-state electrochemical reaction brings about a concentration gradient across the interface. Assuming a charge transfer reaction virtually at equilibrium, the concentration overpotential is defined (1) as the difference between the steady-state potential and the potential across the interface obtained at the open circuit (equilibrium potential). Using activity terms rather than concentration in the Nernst equation, the concentration overpotential $\left(\eta_{\mathrm{c}}\right)$ for an electronation reaction can be expressed in the following form

$$
\eta_{\mathrm{c}}=\frac{R T}{n \mathbf{F}} \ln \frac{a_{x=0}}{a^{0}}
$$

where $a_{x=0}$ is the activity of the reacting species at the interface in $g$ ions $/ 1$, and $a^{0}$ is the activity of the same species in the bulk in $g$ ions/l. According to the Fick's law of steady-state diffusion, assuming a known and virtually constant activity coefficient, $a^{\circ}-a_{x=0}$ is proportional to the current density

$$
a^{\circ}-a_{x=0}=-\frac{i \delta}{n F D} \times 10^{3}
$$

where $i$ is the current density in $\mathrm{A} / \mathrm{cm}^{2}, \delta$ is the diffusion layer thickness in $\mathrm{cm}$, and $D$ is the diffusion co- efficient of the reacting species in $\mathrm{cm}^{2} / \mathrm{s}$. By introducing Eq. [2] in Eq. [1], one obtains

$$
\eta_{\mathrm{c}}=\frac{R T}{n \mathbf{F}} \ln \left(1+\frac{10^{3} i \delta}{n \mathbf{F} D a^{\circ}}\right)
$$

An inherent property ${ }^{1}$ of expression [3] is the $\eta_{\mathrm{c}}$ 's linear dependence on current density for small values of $10^{3} \frac{i \delta}{n \mathbf{F} D} / a^{\circ}$. For such operating conditions, Eq. [3] may be written as

$$
\eta_{\mathrm{c}}=i \frac{R T \delta 10^{3}}{n^{2} \mathbf{F}^{2} D a^{0}}
$$

or

where

$$
\eta_{\mathrm{c}}=K \cdot \boldsymbol{i}
$$

$$
K=\frac{R T \delta 10^{3}}{n^{2} \mathbf{F}^{2} D a^{0}}
$$

For example, for a single electron charge transfer reaction for $a^{\circ}=1 \mathrm{~g}$ ion $/ 1 . \mathbf{F}=9.65 \times 10^{4} \mathrm{As} / \mathrm{g}$ ion, $D=10^{-5} \mathrm{~cm}^{2} / \mathrm{s}$ at current density of $10^{-3} \mathrm{~A} / \mathrm{cm}^{2}$, and

$$
\lim _{x \rightarrow 0}(1 \pm x)= \pm x
$$

